european journal of histochemistry

a journal of functional cytology

$$
\begin{gathered}
\text { ISSN 1121-760X } \\
\text { volume 56/supplement } 1 \\
2012
\end{gathered}
$$

\title{
XXII ANNUAL MEETING OF THE ITALIAN GROUP FOR ULTRASTRUCTURAL PATHOLOGY \\ SIAPEC - GIPU
}

Urbino, Italy, June 29-30, 2012 University of Urbino "Carlo Bo"

\section{Presidents}

E. Falcieri, G. Cenacchi

Scientific Programme Committee

S. Burattini, L. Badiali De Giorgi

Local Organizing Committee

E. Fucili, S. Salucci, D. Curzi, V. Baldassarri 


\section{Published by PAGEPress, Pavia, Italy}

\section{Editorial Office:}

via G. Belli 7, 27100 Pavia, Italy

Phone: +39.0382.1751762 - Fax: +39.0382.1750481

E-mail: info@pagepress.org

\section{Printed quarterly by:}

Tipografia PIME Editrice srl

via Vigentina 136

27100 PAVIA, Italy

Phone: +39.0382.572169 - Fax +39.0382.572102

E-mail: tipografia@pime-editrice.it

\section{Annual Subscriptions}

Europe: Euro 160

All other Countries: \$200

Subscriptions, cancellations, business correspondence and any enquiries must be sent to PAGEPress Publications, Pavia, Italy.

Cancellations must be received before the end of September to take effect at the end of the same year.

No part of this publication may be reproduced, stored in a retrieval system or transmitted in any form or by any means (electronic, electrostatic, magnetic type, mechanical, photocopying or otherwise] without written permission by the Publishers.

Reg. Tribunale di Pavia n. 289/23.2.1984.

Supported by the Ministero per i Beni e le Attività Culturali, Italy as a publication of high cultural value.

Disclaimer. Whilst every effort is made by the publishers and the editorial board to see that no inaccurate or misleading data, opinion or statement appears in this journal, they wish to make it clear that the data and opinions appearing in the articles or advertisements herein are the responsibility of the contributor or advisor concerned. Accordingly, the publisher, the editorial board and their respective employees, officers and agents accept no liability whatsoever for the consequences of any inaccurate or misleading data, opinion or statement.

Associato all'USPI
Unione Stampa Periodica Italiana european journal of histochemistry

a journal of functional cytology

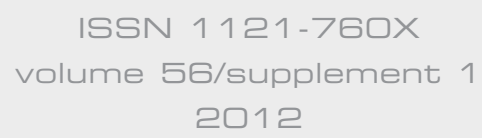




\section{European Journal of Histochemistry a journal of functional cytology}

The European Journal of Histochemistry was founded in 1954 by Maffo Vialli and published untill 1979 under the title of Rivista di Istochimica Normale e Patologica, from 1980 to 1990 as Basic and Applied Histochemistry and in 1991 as European Journal of Basic and Applied Histochemistry. It is published under the auspices of the Università of Pavia and of the Ferrata Storti Foundation, Pavia, Italy.

The European Journal of Histochemistry is the official organ of the Italian Society of Histochemistry and a member of the journal subcommittee of the International Federation of Societies for Histochemistry and Cytochemistry (IFSHC).

The Journal publishes Original papers, Technical reports, Reviews, Brief notes, Letters to the Editor, Book reviews, Views and Comments, concerning investigations performed with the aid of biophysical, biochemical, molecular-biological, enzymatic, immunohistochemical, cytometric, and image analysis techniques.

Areas of particular interest to the European Journal of Histochemistry include:

- functional cell and tissue biology in animals and plants;

- cell differentiation and death;

- cell-cell interaction and molecular trafficking;

- biology of cell development and senescence;

- nerve and muscle cell biology;

- cellular basis of diseases.

Editor-in-Chief

C.E. Pellicciari (University of Pavia, Italy)

\section{Managing Editors}

C.A. Redi (University of Pavia, Italy)

E. Solcia (University of Pavia, Italy)

for Europe: J.E. Scott (University of Manchester, UK) for Japan: M. Fukuda (Fukui Medical School, Fukui, Japan)

for Latin America: R.F. Donoso (University of Chile) for USA and Canada: A. Nanci (University of Montreal, Canada)

Assistant Editor

Manuela Malatesta (University of Verona, Italy)
Managing Board of the Italian Society of Histochemistry for the years 2010-2013

Fiorenza De Bernardi (President), University of Milan Silvano Capitani (Vice President), University of Ferrara

Eugenio Gaudio (Member), "La Sapienza" University of Rome

Antonio De Luca (Member), Second University of Naples

Manuela Malatesta (Secretary), University of Verona Nadir M. Maraldi (Past President), University of Bologna

\section{Editorial Board}

M. Biggiogera, Pavia; B. Bilinska, Warsaw; E. Bonucci, Rome; G. Bottiroli, Pavia; L. Cocco, Bologna; A. Diaspro, Genova; E. Falcieri, Urbino; A. Fasolo, Torino; P. Hozak, Prague; Z. Kmiec, Gdansk; A. Lauria, Milano; H.G. Lee, Cleveland; F.A. Manzoli, Bologna; N.M. Maraldi, Bologna; F.J. Medina, Madrid; G. Meola, Milano; S. Modina, Milano; S. Muller, Strasbourg; P. Panula, Helsinki; M. Pavelka, Vien; G. Perry, San Antonio; G. Rindi, Roma; A. Riva, Cagliari; C. Sotelo, Paris; P.G. Suh, South Korea; J.P. Tremblay, Quebec.

\section{Members appointed by Scientific Societies}

E. Bàcsy (Histochemical Section of the Society of the Hungarian Anatomists), B. Bloch (Societé Française de Microscopie Electronique), A. Lòpez Bravo (Federacion Iberoamericana de Biologia Celular y Molecular), B. Bilinska (Polish Histochemical and Cytochemical Society), M.A. Nahir (Israel Society for Histochemistry and Cytochemistry), D. Onicescu (Romanian Society of Histochemistry and Cytochemistry), W. Ovtscharoff (Histochemical Section of the Society of Anatomy, Histology and Embryology of Bulgaria), P. Panula (Finnish Society of Histochemistry and Cytochemistry), L. J. Pelliniemi (Finnish Society of Histochemistry and Cytochemistry), J. Renau Piqueras (Spanish Society for Cell Biology), B. Rodé (Histochemical and Cytochemical Section of Croatian Society of Anatomists), M. Rosety (Sociedad Iberoamericana de Histoquimica y Citoquimica). 



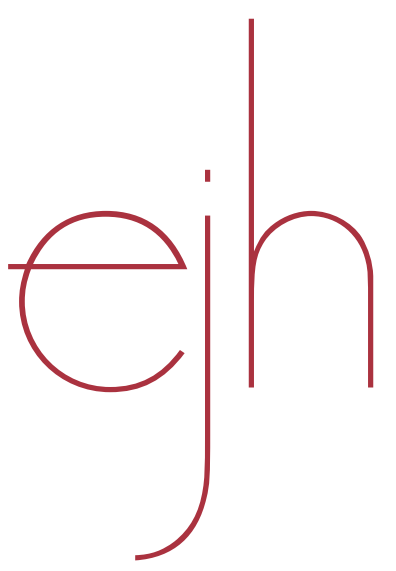

table of contents

XXII ANNUAL MEETING OF THE ITALIAN GROUP FOR ULTRASTRUCTURAL PATHOLOGY

SIAPEC - GIPU

Invited Lectures

.1

Scientific Contributions

.3

Index of authors.

european journal

of histochemistry

ISSN 1121-760X

volume 56/supplement 1

2012 



\title{
XXII ANNUAL MEETING OF THE ITALIAN GROUP FOR ULTRASTRUCTURAL PATHOLOGY SIAPEC - GIPU
}

\author{
Urbino, Italy, June 29-30, 2012 \\ University of Urbino "Carlo Bo", Scientific Campus, Main Hall
}

$\begin{array}{ll}\text { Presidents: } & \text { prof. Elisabetta Falcieri MD, Urbino University } \\ & \text { prof. Giovanna Cenacchi MD, Bologna University }\end{array}$

Scientific Programme Committee: dr. S. Burattini, Urbino

dr. L. Badiali De Giorgi, Bologna

Local Organizing Committee: dr. E. Fucili, dr. S. Salucci, dr. D. Curzi, dr. V. Baldassarri, Urbino

The Italian Group for Ultrastructural Pathology, GIPU, is a section of the Italian Society for Anatomical Pathology and Cytopathology, SIAPEC, and belongs to the Electron Microscopy Working Group, EMWG of the European Society of Pathology. GIPU collects Italian pathologists utilizing transmission and scanning electron microscope [EM] to investigate subcellular alterations which cannot be demonstrated by other morphological techniques such as light microscopy, confocal laser scanning microscopy, and immunohistochemistry in diagnostic and experimental pathology. "The Big Eye" as it was called the electron microscope in the 1960s and 1970s. By the mid1980s, however, the green glow of the electron microscope was partially off: The use of electron microscopy in diagnostic histopathology has declined significantly in recent years, largely as a result of advances in immunocytochemistry and molecular techniques. However, EM remains an important diagnostic tool in several well-defined areas of diagnostics and largely employed in many fields of experimental pathology. Consequently, there is still a need for EM services and labs. The generation of EM images requires highly skilled and specialised scientific staff; the current workforce with these skills is ageing and there is a suspicion that new staff are not being trained to take over their role. GIPU is still devoted to organize training school in EM dedicated to young pathologists and researchers promoting knowledges in the innovative EM methods and techniques.

We would like to acknowledge Professor Elisabetta Falcieri to kindly host this XXII Annual Meeting of GIPU in the beautiful Urbino. The scientific program reflects nearly all the main topics in diagnostic and experimental pathology focusing on neuromyopathology, storage diseases, ciliary dyskinesia, pediatric and reproductive system pathology. Eighteen oral communications will give the opportunity to young ultrastructural pathologists to discuss together and with expert pathologists. 



\section{INVITED LECTURES}

\section{DIAGNOSTIC VALUE OF ELECTRON MICROSCOPY IN CADASIL DISEASE}

M. Morroni, ${ }^{1,2}$ D. Marzioni, ${ }_{1}^{1}$ M. Ragno, ${ }^{3}$ P. Di Bella, ${ }^{4}$ E. Cartechini, ${ }^{5}$ L. Pianese, ${ }^{6}$ T. Lorenzi, ${ }^{1}$ M. Scarpelli ${ }^{7}$

${ }^{1}$ Department of Experimental and Clinical Medicine, Section of Anatomy, School of Medicine, Università Politecnica delle Marche and 'Electron Microscopy Unit, United Hospitals, Ancona, Italy; ${ }^{3}$ Division of Neurology, Mazzoni Hospital, ASUR ZT 13, Ascoli Piceno, Italy; ${ }^{4}$ Department of Neurosciences, School of Medicine, Università Politecnica delle Marche, United Hospitals, Ancona, Italy; ${ }^{5}$ Division of Neurology, Macerata Hospital, ASUR ZT 9, Macerata, Italy; ${ }^{6}$ Molecular Medicine Laboratory, Mazzoni Hospital, ASUR ZT 13, Ascoli Piceno, Italy; 'Department of Biomedical Sciences and Public Health, Section of Pathological Anatomy, School of Medicine, Università Politecnica delle Marche, United Hospitals, Ancona, Italy

E-mail:m.morroni@univpm.it

Objectives: Cerebral autosomal dominant arteropathy with subcortical infarcts and leukoencephalopathy (CADASIL) is caused by mutations in NOTCH3 gene encoding a transmembrane receptor notch3..$^{1,2}$ The mutations result in a degeneration of vascular smooth muscle cells (VSMCs). ${ }^{3}$ In electron microscopy (EM), the pathognomonic features of CADASIL is accumulation of granular osmiophilic material (GOM) in indentations of the VSMCs or in the extracellular space in close vicinity to VSMCs detectable in some tissues such as skin. ${ }^{4}$ Although GOM has been considered specifically diagnostic for CADASIL, some authors do not consider the sensitivity of detecting GOMs in tissue biopsies equal to $100 .{ }^{5}$ On the contrary, the aim of this study is to demonstrate that the diagnostic sensitivity for CADASIL using EM is equal to 100 .

Methods: We have studied 31 suspected CADASIL cases by EM and genetic investigations using skin, skeletal muscle, kidney and pericardial biopsies.

Results: Our results demonstrate that the cases with strong clinical suspect (12 out of 31 patients) were positive for GOMs detected by EM technique. They were also positive for NOTCH3 mutations. GOMs were never found in patients (19 cases) without mutations.

Conclusion: These results give to this technique $100 \%$ specificity and sensitivity for the diagnosis of CADASIL.

1. Tournier-Lasserve E et al. Nat Genet 1993, 3:256-259.

2. Joutel A et al. Nature 1996, 383:707-710.

3. Joutel A et al. J Clin Invest 2000, 105:597-605.

4. Baudrimont M et al. Stroke 1993, 24:122-125.

5. Markus HS et al. 2002, 59:1134-1138.

\section{EXTRACELLULAR MATRIX MYOPATHIES: ULTRASTRUCTURAL AND FUNCTIONAL ASPECTS}

P. Sabatelli, ${ }^{1}$ C. Pellegrini, ${ }^{2}$ F. Tagliavini, ${ }^{1}$ F. Sardone, ${ }^{1}$ L. Merlini ${ }^{3}$

${ }^{1} I G M-C N R$, Unit of Bologna, clo IOR, Bologna, Italy; ${ }^{2}$ Department of Experimental and Diagnostic Medicine, Section of Medical Genetics, University of Ferrara, 44100 Ferrara, Italy: ${ }^{3}$ Medicina Fisica e Riabilitazione, Dipartimento Rizzoli-Sicilia, IOR, Bagheria (PA), Italy

The sarcolemma of each individual skeletal muscle fiber is closely associated with an extracellular matrix layer, the base- ment membrane (BM), which is composed by an internal feltlike layer and an external reticular lamina. Genetic evidence has revealed that congenital muscular dystrophies can arise from the loss of components in the extracellular matrix proteins. Mutations in LAMA2 gene, which encodes the laminin alpha 2 chain, a major constituent of muscle fiber basal lamina, cause Congenital Muscular Dystrophy 1A, ${ }^{1}$ Basement membrane disruption and increased rate of apoptosis has been reported in laminin alpha2 chain deficient muscles. Alpha-dystroglycan provides a linkage between laminin alpha 2 and the cytoskeleton. The capacity of binding of alpha-dystroglycan depends on its extensive post-translational glycosylation, and this has emerged as a convergent target for a group of limb-girdle and congenital muscular dystrophies termed "secondary dystroglycanopathies", ${ }^{2}$ Alpha-dystroglycan binds perlecan, a ubiquitous heparan sulfate proteoglycan that is secreted into basement membranes. It is encoded by HSPG2 gene and lossof-function mutations cause myopathy associated with myotonia. Collagen VI, a perlecan binding protein, localizes in the reticular layer of the basement membrane, perimysium and endomysium. Mutations in the collagen VI genes are known to cause Ullrich congenital muscular dystrophy (UCMD), Bethlem myopathy (BM) and Myosclerosis myopathy (MM). Patients muscle biopsies display ultrastructural defects of the sarcoplasmic reticulum (SR) and mitochondria, spontaneous apoptosis, ${ }^{3}$ and altered autophagic mechanism activation.

The ECM has long been viewed as an amorphous scaffold that provides mechanical support. The identification of specific mechanisms downstream ECM genetic defects may better define the role ECM in regulating muscle functions.

1. Gawlik KI and Durbeej M.Skelet Muscle. 2011 Mar 1;1(1):9.

2. Muntoni F, et al., Curr Opin Neurol. 2011 Oct;24(5):437-42.

3. Angelin A, et al., Proc Natl Acad Sci U S A. 2007 Jan $16 ; 104(3): 991-6$.

\section{ULTRASTRUCTURAL EXAMINATION OF SKIN BIOPSY FOR THE DIAGNOSIS OF NEUROLOGICAL DISEASES. PAST, PRESENT AND FUTURE}

M. Morbin

IRCSS Foundation Istituto Neurologico "C. Besta", Milano, Italy

E-mail: morbin@istituto-besta.it

The use of ultrastructural examination of skin biopsy for the diagnosis of neurological disorders started in the early 1970 s after the description of the presence of similar electron microscopy (EM) changes in skin and nerve tissue from patients with Hurler's disease. ${ }^{1}$

Successively a large body of evidence has made the skin biopsy crucial for the diagnosis of several neurological diseases and for the study of their pathogenesis. ${ }^{2}$

In particular, skin biopsy was considered mandatory for the diagnosis of ceroid-lipofuscinosis (NCL), Infantile Axonal Neuroaxonal dystrophy (INAD), mucolipidosis IV and Lafora disease and a useful tool for screening other Lysosomal Storage Diseases (LSD). ${ }^{2}$

In the early 2000 s the success in identifying genes and their mutations has set the stage for DNA-based diagnosis of LSD. However, even though the majority of diseases can be diagnosed using DNA or biochemical analyses, the morphological study is still mandatory when these procedures are not informative.

Recent studies have demonstrated that the examination of skin biopsies is able to exclude more than $90 \%$ of cases in which LDS is being considered, and that it is the most cost-effective 
screening tool in patients with previously unrecognized storage diseases. ${ }^{3,4}$

Moreover it has been reported that some neurodegenerative pathologies, such as ferritinopathy, ${ }^{5}$ neuronal intranuclear inclusion disease ${ }^{6}$ and a-synnucleinopathies ${ }^{7}$ can be diagnosed using skin biopsy.

Based on current knowledge it is likely that the EM examination of skin biopsy in the future will maintain its role for preliminary identification of new disorders, for diagnostic work-up to confirm or rule out a storage disorders and for identify some neurodegenerative disorders. In addition it is expected that skin biopsy will be a cost-effective outcome measure to evaluate the efficacy of new therapies for LSD.

1. DeCloux RJ \& Friederici HH, Arch Pathol, 1969, 88:350-58.

2. Ceuterick C \& Martin JJ. Brain Pathol 1998 Jan;8(1):121-32.

3. Alroy J \& Ucci AA. Ultrastruct Pathol 2006 30:489-503.

4. Papa V et al. Ultrastruct Pathol 2010 34:243-51.

5. Vidal RJ et al. Neuropathol Exp Neurol 2004, 63:363-380.

6. Sone $\mathrm{J}$ et al. Neurology 2011;76:1372-1376 .

7. Yasuo M et al. Neurosci Lett 2010; 46 9357-359.

\section{CNS TUMORS AND ULTRASTRUCTURAL DIAGNOSIS}

G. Cenacch

Dip. Clinico Scienze Radiologiche e Istocitopatologiche, Alma Mater Studiorum Università di Bologna, Italy

The rise of immunohistochemistry, ICC, provided insight into molecular expressions that rendered mere structure seemingly obsolete. And yet, as powerful as ICC has proven to be, there remain areas especially of diagnostic neuropathology, where electron microscopy, EM, provides diagnoses that cannot be achieved by ICC or by any other technique. The World Health Organization, WHO, classifies brain tumors on the basis of their cellular origins in the central nervous system, CNS. Light microscopy, ICC, and EM manifest cellular and intracellular morphology and characteristics suggesting their cellular origins. While well-differentiated CNS tumors with classic histological appearances are easily identified on routine histological examination, there are often areas of overlap in the histological appearance of different tumors, yielding look-alikes. EM is useful in the differential diagnosis of these tumors. This problem is an especially thorny one with tumors of the spinal canal, where ependymomas and astrocytomas and even schwannomas and meningiomas can share histological features. Similarly, neurogenic tumors of the peripheral nervous system can be confused with other spindlecell tumors. And both central neurocytoma and clear cell ependymoma can mimic the histological appearance of oligodendroglioma. Tumors for which EM is useful include also unusual or atypical variants of meningioma, ependymoma, and schwannoma and small "blue cell" tumors of childhood. EM remains the gold standard of diagnosis for some tumor types, such as ependymoblastoma, choroid plexus carcinoma, and plexosarcoma. EM has played an important role in the diagnosis and establishment of new tumor entities and variants and it is of great value in identifying site of origin for metastatic adenocarcinomas of unknown origin, an under-recognized and under-utilized potential for this technique. In contrast, EM is not useful in the determination of malignancy, which is better accomplished by light microscopy. Even tissue retrieved from paraffin blocks, although less satisfactory, can be used for EM and can provide diagnostic answers in some situations. Promptness of fixation and neutral $\mathrm{pH}$ are far more important than other considerations, and tissue that has been fixed in buffered formalin soon after receipt is far preferable to tissue that has been held "fresh" for later glutaraldehyde fixation.

\section{ULTRASTRUCTURAL CHANGES OF HUMAN OOCYTE AFTER CRYOPRESERVATION}

S.A. Nottola, ${ }^{1}$ G. Macchiarelli ${ }^{2}$

${ }^{1}$ Dept of Anatomy, Histology, Forensic Medicine and Orthopaedics, La Sapienza University, Rome and ${ }^{2}$ Dept. of Health Sciences, University of I'Aquila. Italy

E-mail: gmacchiarelli@hotmail.com

Preservation of subcellular integrity is a major issue in the validation of human oocyte cryopreservation protocols in ART. ${ }^{1}$ Our aims were to evaluate the main ultrastructure changes occurring in human mature oocytes after slow freezing and vitrification. Therefore, MII human oocytes (obtained after informed consent) were fixed at sampling (fresh controls) and after freeze/thawing and were processed for light and transmission electron microscopy observations. ${ }^{1,2}$ The following structural and ultrastructural characteristics of the oocyte have been especially evaluated: $:^{1-3}$ general features (e.g. shape, dimensions, density of ooplasma); integrity of germinal vesicle (in immature oocyte) and, in favorable sections, the arrangement of the MII spindle (spindle reassembly and chromosome alignment); ooplasmic vacuoles, lysosomes, multivesicular bodies; microtopography of the organelles (mitochondria; mitochondria-smooth endoplasmic aggregates; mitochondria-vesicle complexes); cortical granule (CG) pattern and zona pellucida (ZP) texture; integrity of oolemma. Our results demonstrated that cryopreserved oocytes presented rounded shaped ooplasm with a continuous oolemma, intact ZP and uniformly distributed organelles, as seen in control fresh oocytes. Numerous vacuoles were found after slow freezing, whereas the vacuoles were only occasionally detected in fresh controls and after vitrification. Amount and density of CG appeared abnormally reduced in all cryopreserved oocytes. It is concluded that even if cryopreservation may ensures a good overall preservation of the oocyte, nevertheless, vacuolization appears as a recurrent form of cell damage during slow freezing. ${ }^{1-3}$ In addition the premature CG exocytosis - and the consequent hardening of the ZP - is an indication for the use of ICSI as the preferred insemination method after cryopreservation.

1. Nottola SA et al. Hum Reprod. 2007, 22:1123-33.

2. Nottola SA et al. Reprod Biomed Online. 2008, 17:368-77.

3. Nottola SA et al. Reprod Biomed Online. 2009, 19:17-27.

\section{THE ROLE OF ELECTRON MICROSCOPY IN NEONATAL PULMONARY PATHOLOGY}

R. Boldrini, ${ }^{1}$ D. Peca, ${ }^{2}$ S. Petrini, ${ }^{2}$ A. Citti, ${ }^{1}$ O. Danhaive ${ }^{3}$

${ }^{1}$ Dept of Pathology and ${ }^{2}$ Research Laboratories Bambino Gesù Pediatric Hospital, IRCCS Rome, Italy; ${ }^{3}$ Infant Care Center San Francisco General Hospital, San Francisco USA

Electron microscopy study of lung biopsies performed in term neonates with severe respiratory distress syndrome not responsive to surfactant replacement represents a good tool for identifying inherited disorders of surfactant proteins, allowing a focused genetic evaluation. ${ }^{1}$ Light microscopy in these cases shows a variable combination of interstitial pneumonia with type II pneumocytes hyperplasia and pulmonary alveolar proteinosis. Electron microcopy reveals a reduction in number of lamellar bodies in apical cytoplasm of type II pneumocytes and characteristic morphologic anomalies: while multivesicu- 
lar bodies suggest SP-Bdeficiency, small and compact lamellary bodies with electron-dense cores suggest $A B C A 3$ deficiency. But other rare lung diseases can be identified in term newborns with severe respiratory distress syndrome with the aid of electron microscopy study. Pulmonary glycogenosis is a rare entity characterized by thickening of the interstitium due to overloading of monoparticulate glycogen in immature mesenchymal interstitial cells. The etiology is unknown but the most suggestive hypothesis is that of a disorder due to dismaturity of the interstitial cells, in relation to beneficial effects of corticosteroid therapy and frequent favorable outcome. ${ }^{2}$ Alveolar capillary dysplasia is a developmental disorder characterized by decreased number and internalization of alveolar septal capillaries and misalignment of lung vessels. ${ }^{3}$ A newborn with alveolar capillary dysplasia and anomalies of lamellary bodies suggestive for ABCA3 deficiency, was found to carry a singleABCA 3 missense mutation. This case bears some analogy with the one described by Kunig ${ }^{4}$ suggesting that the two conditions could be related. ${ }^{5}$ The ultrastructural study of lung biopsy is very useful in identifying disorders of surfactant metabolism, allowing genetic evaluation and distinguishing them from others neonatal lung anomalies.

1. Wert SE et al. Pediatr Dev Pathol 2009, 12; 253-74.

2. Canakis AM et al. Am J Respir Crit Care Med 2002, 165; 1557-65.

3. Dishop MK et al. Pediatr Resp Reviews 2011, 12; 230-237.

4. Kunig AM et al. J Pediatr 2007, 151; 322-4.

5. Danhaive 0 et al. J Pediatr 2008, 152; 891-2.

\section{SCIENTIFIC CONTRIBUTIONS}

\section{SKELETAL MUSCLE CELL BEHAVIOR AFTER CHEMICAL APOPTOTIC INDUCTION}

S. Salucci, ${ }^{1}$ B. Canonico, ${ }^{1,2}$ V. Baldassarri, ${ }^{1}$ S. Burattini, ${ }^{1}$ M. Battistelli, ${ }^{1}$ S. Papa, ${ }^{1,2}$ E. Falcieri'1,3

${ }^{1}$ DiSTeVA and ${ }^{2}$ Centro di Citometria, University of Urbino "Carlo Bo", Urbino; ${ }^{3}$ IGM-CNR, Istituti Ortopedici Rizzoli, Bologna; Italy

E-mail:sara.salucci@uniurb.it

Apoptosis is considered necessary to regulate proliferation, differentiation and homeostasis in skeletal muscle cells. ${ }^{1}$ Inappropriate apoptosis is pathogenetic in several dystrophies and myopathies, in denervation and disuse. ${ }^{2}$ The aim of this work is to study in vitro, in $\mathrm{C} 2 \mathrm{C} 12$ myoblasts and myotubes, the apoptotic process induced by chemical triggers with different mechanisms of action.

For this purpose, we induced apoptosis with etoposide, staurosporine and $\mathrm{H}_{2} \mathrm{O}_{2}$, and cell response was investigated by means of cytofluorimetric and morphological analyses.

We found that myoblasts appeared more sensitive than myotubes to all chemical treatments. In particular, myoblasts treated with etoposide, a topoisomerase II inhibitor, showed a characteristic apoptotic behavior, with chromatin margination and condensation, while in myotubes apoptotic and normal nuclei appeared inside the same syncytium. ${ }^{3}$ Cells treated with staurosporine, a PKC blocking agent, evidenced late apoptotic features and secondary necrosis. After $\mathrm{H}_{2} \mathrm{O}_{2}$ exposure, myotubes, differently from myoblasts, showed a poor cell sensitivity to cell death.

Intriguingly, autophagic granules diffusely appeared in myotubes after each treatment.

The lower apoptotic rate in myotubes, compared to myoblasts, could be linked to their differentiation stage. In fact, myogenic cells acquire an apoptosis-resistant phenotype during differentiation, due to cell death inhibitors increase. ${ }^{4}$ In addition, autophagy, mostly occurring in myotubes, could preserve and maintain muscle cell integrity against chemical stimuli, most of which activate death pathways involving mitochondria. Thus, autophagy, now considered an important mechanism for mitochondria degradation, ${ }^{5}$ plays a central role in muscle biology and, in particular, in cell death-resistance of differentiated cells.

1. Ferreira R et al. Physiol Res 2008, 57:601-611.

2. Dupont-Versteegden EE. World J Gastroenterol 2006, 12:74637466.

3. D'Emilio et al. Histol Histopathol 2010, 25:21-32.

4. Xiao R et al. Apoptosis 2011, 16:221-34.

5. Wohlgemuth SE et al. Exp Gerontol 2010, 45:13-148.

\section{ELECTRON MICROSCOPY IN THE MYOFIBRILLAR MYOPATHY DIAGNOSIS}

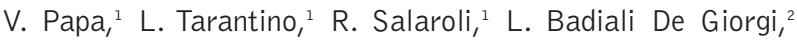
E. Pegoraro, ${ }^{3}$ M. Fanin, ${ }^{3}$ C. Angelini, ${ }^{3}$ G. Cenacchi ${ }^{1}$

${ }^{1}$ Dipartimento Clinico Scienze Radiologiche ed Istocitopatologiche, Alma Mater Università di Bologna; ${ }^{2}$ U.O. Anatomia e Istologia Patologica, Azienda Ospedaliero-Universitaria di Bologna, Policlinico S.Orsola-Malpighi, Bologna; ${ }^{3}$ Dipartimento di Neuroscienze and VIMM, Università di Padova, Italy E-mail: giovanna.cenacchi@unibo.it

Myofibrillar myopathies (MFMs) are rare inherited or sporadic progressive neuromuscular disorders with considerable 
clinical and genetic heterogeneity. ${ }^{1}$ Distal muscles are often involved, and cardiomyopathy and peripheral neuropathy can be associated features. Muscle biopsies from MFM patients show primary degeneration of the muscle fibers, increased fibrosis, as well as necrotic and regenerating fibers. ${ }^{2}$ MFMs are also defined morphologically by foci of myofibril dissolution, accumulation of myofibrillar degradation products, and ectopic expression of multiple proteins. Our purpose was to emphasize how in six different cases electron microscopy (EM) demonstrates submicroscopic abnormalities pathognomonic of desmin accumulation, disintegration of myofibrils that begins at or in immediate proximity of the Z-disc- or similar to myofibrillar disarry, rods, actin- and desmin-like aggregates, transversal reorientation of sarcomere- a MFM. Moreover, ultrastructural findings in MFMs, including prominent Z-disc changes, distinct types of accumulations and nuclear abnormalities, could be useful to reveal clues for identifying the mutated gene. To date, mutations in six genes are known to cause MFM. These genes encode mainly sarcomeric Z-disc proteins or Z-disc-related protein. Additionally, mutations in fourand-a-half-LIM protein I ( FHLI) have recently been shown to cause MFM. ${ }^{1}$ Finally in suspected MFM/protein aggregate myopathy cases, EM analysis (togheter with light microscopy and immunohistochemistry) ${ }^{3}$ should particularly focus on the identification of pathological protein aggregation and signs of myofibrillar degeneration because these alterations could be also discovered in other neuromuscular disorders. ${ }^{4}$

1. Kristl G. Claeys et al. Acta Neuropathol 2009, 117:293-307.

2. Duygu S. Neuromusular Disorders 21 (2011) 161-171.

3. Vattemi G et al. Acta Myologica 2011, 121-126.

4. Rolf S. et al. Brain Pathology 19 (2009) 483-492.

\section{THE MANDATORY ROLE OF MUSCLE BIOPSY IN SPORADIC IBM: A CASE REPORT}

R. Salaroli, ${ }^{1}$ R. Rinaldi, ${ }^{2}$ M. Fusconi, ${ }^{3}$ C. Graziano ${ }^{4}$

L. Badiali De Giorgi, ${ }^{5}$ V. Papa, ${ }^{1}$ L. Tarantino, ${ }^{1}$ C. Tonon,

R. Lodi, ${ }^{1}$ G. Cenacchi ${ }^{1}$

${ }^{1}$ Laboratorio di Patologia e Diagnostica Subcellulare, Dipartimento Clinico di Scienze Radiologiche ed Istocitopatologiche; 'Dipartimento di Medicina Interna, dell'Invecchiamento e Malattie Nefrologiche, Università di Bologna; ${ }^{3}$ Medicina Interna, ${ }^{4}$ Genetica Medica, ${ }^{5}$ Anatomia Patologica, Policlinico S.Orsola-Malpighi, Bologna

E-mail: roberta.salaroli@unibo.it

Inclusion body myositis (IBM) is the most frequent acquired myopathy in patients over 50 years of age but, sometimes, the diagnosis is missed because of a lack of suspicion on the part of physicians. ${ }^{1}$ In the evaluation of progressive weakness in older people, IBM should be an important diagnostic consideration as the following case report underlines. We describe a 71 years old women, without family history of neuromuscular disorders, who has been in good health up to 65 years when she developed progressive and symmetric proximal weakness. Distal muscles were unaffected and dysphagia was absent. CK levels was normal and EMG showed myogenic abnormalities. Clinical data could suggest a facio-scapulo-humeral muscular dystrophy while from Muscle MR analysis a laminopathy has been suspected. Mutations in FSHMDIA and LMNA haven't been identified. Light microscopy showed rimmed vacuoles and invasion of non-necrotic muscle fibres by mono nuclear cells. Immunostaining for MHC-I revealed widespread sarcoplasmic labeling. Electron microscopy described the presence of myelinoid bodies in the sarcoplasm and aggregates of filaments both in the nucleus and in the sarcoplasm. Therefore the muscle biopsy was mandatory and allowed the diagnosis of sporadic IBM.

1. Sunil K. Munshi et al. Age and Ageing 2006, 35: 91-94.

\section{ULTRASTRUCTURAL MODIFICATIONS OF MYOTENDINOUS JUNCTION IN HINDLIMB SUSPENDED RATS}

D. Curzi, ${ }^{1}$ S. Burattini, ${ }^{1}$ J.G. Tidball, ${ }^{2}$ E. Falcieri ${ }^{1,3}$

${ }^{1}$ Dep. of Earth, Life and Environmental Sciences, University of Urbino "Carlo Bo", Urbino; Italy; ${ }^{2}$ Molecular, Cellular and Integrative Physiology Program, University of California, Los Angeles, CA 90095-1606; USA; ${ }^{3}$ Inst. of Molecular Genetics and Istituti Ortopedici Rizzoli, Bologna, Italy

E-mail: davide.curzi@uniurb.it

Myotendinous junction (MTJ) is the region that transmits the skeletal muscle contraction to its tendon and, at its level, the proximal extremity of tendon forms finger-like processes, penetrating into the muscle mass.

In a recent work we demonstrated that changes in the MTJs occurred as an adaptation to exercise-induced tension increase. The branching of the finger-like processes enlarge the whole tendon-muscle surface area, therefore allowing a better tension resistance. ${ }^{2}$

In this study 4 hindlimb suspended and 4 control rats were studied. ${ }^{3}$ After sacrifice, MTJs of plantaris muscle were withdrawn, fixed in $1.4 \%$ glutaraldehyde in $0.2 \mathrm{M}$ sodium cacodylate and processed as previously described. ${ }^{4}$

Sections were stained and observed with a Philips CM 10 electron microscope. 5

After 5 days of suspension, skeletal muscle highlights signs of atrophy in response to decreased mechanical loading. ${ }^{6}$ In fact, at muscle-tendon interface misaligned sarcomeres, with absent Z-lines, were observed. A lower number of, characteristically not bifurcated, muscle-tendon interdigitations also appears. Muscle fiber intermyofibrillar component spreads, especially between terminal filaments and tendon finger-like processes. In conclusion, along with muscle atrophy, ultrastructural changes occur at MTJ organization level, as an adaptation to muscle unloading.

1. Ciena AP et al. Micron 2010, 41(8):1011-14.

2. Curzi D et al. Eur J Histochem 2012, 56:e19.

3. St Pierre BA and Tidball JG. Am J Pathol 1994, 145(6):1463-71.

4. Tidball JG and Quan DM. J Appl Physiol 1992, 73(1):59-64.

5. D'Emilio A et al. Histol Histopathol 2010, 25(1):21-32.

6. Linderman JK et al. Am J Physiol 1994, 267(2 Pt2):R365-71.

\section{MELATONIN ROLE IN THE PREVENTION OF SKELETAL MUSCLE APOPTOSIS}

V. Baldassarri, ${ }^{1}$ S. Salucci, ${ }^{1}$ D. Curzi ${ }^{1}$ B. Canonico, ${ }^{1}$

S. Burattini, ${ }^{1}$ S. Papa, ${ }^{1}$ E. Falcieri ${ }^{1,2}$

${ }^{1}$ Dep. of Earth, Life and Environmental Sciences, University of Urbino "Carlo Bo", Urbino; "Inst. of Molecular Genetics, CNR and Istituti Ortopedici Rizzoli, Bologna, Italy

E-mail: valentina.baldassarri@uniurb.it

Melatonin has a wide range of physiological functions: it influences circadian rhythms, stimulates the immune system, has anti-inflammatory and onco-static effects and provides protection against oxidative stress. The latter function is carried out through its ability to act, directly, as a free radical scavenger and, indirectly, by stimulating antioxidant enzymes 
production. ${ }^{1}$ Oxidative stress, defined as the imbalance between free radical generation and antioxidant defense mechanisms, is a major player in initiating apoptotic cell death in skeletal muscle, as well as in other tissues. Apoptosis is essential for skeletal muscle development and homeostasis; nevertheless, its misregulation has been frequently observed in several myopathies, ${ }^{2}$ in sarcopenia, as well as in denervation and disuse. Several authors demonstrated that melatonin exerts anti-apoptotic actions in various cell models. ${ }^{3}$ Moreover, our previous studies evidenced that melatonin prevents apoptosis induced by UV-B and $\mathrm{H}_{2} \mathrm{O}_{2}$ in $\mathrm{U} 937$ cells. ${ }^{4,5}$

In this work, melatonin activity has been investigated in $\mathrm{C} 2 \mathrm{C} 12$ skeletal muscle cells, after various apoptotic chemical treatments, chosen for their different mechanisms of action, all determining radical oxygen species (ROS) increase. Cells were pretreated with melatonin and then exposed to $\mathrm{H}_{2} \mathrm{O}_{2}$, staurosporine and etoposide. Data obtained, by means of ultrastructural techniques and cytometric analyses, show that melatonin prevents apoptosis induced by $\mathrm{H}_{2} \mathrm{O}_{2}$ and, to a lesser extent, by etoposide. Differently, staurosporine-induced apoptosis is not inhibited, probably because staurosporine triggers apoptosis with a mechanism of action different from ROS increase.

These preliminary results confirm melatonin ability to act as an antioxidant and anti-apoptotic molecule, thus suggesting a possible therapeutic strategy for myophaties involving apoptosis misregulation.

\footnotetext{
1. Allegra M et al. J Pineal Res 2003, 34:1-10.

2. Loro E et al. Cell Death Differ 2010, 17:1315.

3. Hibaoui $Y$ et al. J Pineal Res $2009,47: 238-52$.

4. Luchetti $F$ et al. J Pineal Res 2006, 40:158-67.

5. Salucci S et al. Microscopie 2010, 13:51-57.
}

\section{IMMUNO-ELECTRON MICROSCOPY IN THE DIAGNOSIS OF SYSTEMIC AMYLOIDOSES}

L. Verga, ${ }^{1}$ G. Capello, ${ }^{1}$ G. Palladini, ${ }^{2}$ P. Morbini, ${ }^{1}$ A. Foli, ${ }^{2}$

G. Merlini, ${ }^{2}$ M. Paulli ${ }^{1}$

${ }^{1}$ Pathology Unit and ${ }^{2}$ Amyloidosis Research and Treatment Center, Fondazione IRCCS Policlinico San Matteo and University of Pavia, Italy

E-mail:I.verga@smatteo.pv.it

Systemic amyloidoses are disorders of diverse etiology, either hereditary or acquired, in which abnormally folded proteins deposit in organs, leading to destruction of tissues and progressive disease. Recent advances in the treatment of systemic amyloidoses emphasize the importance of an early diagnosis, which requires histological demonstration of amyloid deposits. ${ }^{1}$ Definitive typization of the deposited amyloidogenic protein is crucial for a correct diagnosis, appropriate treatment, assessment of prognosis, and genetic counseling. ${ }^{2}$ Fineneedle aspiration of abdominal fat and salivary gland biopsy represent valid alternatives to organ biopsy. The ultrastructural examination of biopsy samples is capable of confirming or ruling out the diagnosis of amyloidosis $\mathrm{s}^{3,4}$ and can identify even very small deposits of amyloid fibrils. ${ }^{1}$ By electron microscopy, whatever the protein may be, amyloid deposits appear as randomly oriented, non-branching fibrils measuring 8-10 nm in diameter. Light microscopic immunohistochemical differentiation among different types of amyloid fibril proteins may be difficult and carries a high rate of false positive results due to unspecific stain. ${ }^{5}$ In contrast, immuno-electron microscopy can correctly characterize amyloid deposits in over $99 \%$ of specimens, including tissues that are easy to sample, such as abdominal fat and minor salivary glands. When both the abdominal fat and salivary gland biopsies do not show amyloid deposits but systemic amyloidosis is suspected, and in patients with localized amyloidosis, a biopsy of the affected organ or site is needed for diagnosis. Immuno-electron microscopy can correctly characterize the amyloidogenic protein in all the commonest forms of amyloidosis, i.e. $A L, A A, A T T R, A \beta 2 M$ and AApoAI.

1. Verga L et al., eds. MM Picken, A Dogan, GA Herrera, Springer, New York, April 2012.

2. Merlini G, Bellotti V. N Engl J Med 2002;349:583-596.

3. Arbustini E et al., Amyloid: Int J Exp Clin Invest 1997;4:157-170.

4. Gertz MA Am J Clin Pathol 2004;121:787-789.

5. Picken MM Arch Pathol Lab Med 2010;134:545-551.

\section{ORIGIN OF WHITE AND BROWN ADIPOSE CELLS FROM VASCULAR ENDOTHELIUM}

A. Frontini, ${ }^{1}$ K. van Tran, ${ }^{2}$ O. Gealekman, ${ }^{2}$ M.C. Zingaretti, ${ }^{1}$ S. Corvera, ${ }^{2}$ S. Cinti $^{1}$

${ }^{1}$ Department of Experimental and Clinical Medicine, University of Ancona (Politecnica delle Marche), Ancona, Italy; 'Program in Molecular Medicine, University of Massachusetts Medical School, Worcester, MA 01605, USA E-mail: cinti@univpm.it

Introduction: Adipose tissue expansion involves the enlargement of existing adipocytes, the differentiation of adipocyte progenitors, and the development of the supporting vascular network. Although some data suggest that the adipocyte progenitors reside in the vasculature of the adipose tissue, their identity is not completely clear., ${ }^{1,2}$ Here we address the hypothesis that a population of adipocytes derives from an endothelial cell (EC) lineage.

Methods: We performed a detailed morphological analysis in developing murine WAT and BAT in order to highlight the features of adipocyte precursors. In addition, we used the VECadherin-Cre/R26R mouse model to address the relationship between vascular ECs and adipose cells development. This lineage tracing model allowed the identification of cells that express the EC gene VE-Cadherin at any point during differentiation. Finally, we analyzed capillary sprouts arising from human subcutaneous fat tissue to evaluate the hypothesis that ECs forming these structures possess the capacity to transform into adipocytes.

Results: Ultrastructural analysis of discrete areas of intense adipogenesis, that we designated vasculo-adipocytic islets, revealed the presence of rare endothelial-pericytic cells that could represent an intermediate developmental step between the EC and the preadipocyte stage. Lineage tracing experiments using the $\mathrm{VE}$-cadherin promoter revealed the expression of reporter genes in ECs, preadipocytes and adipocytes in white and brown fat depots. Furthermore, capillary sprouts (which have predominantly EC characteristics) from human adipose tissue were found to express Zfp423, a recently identified marker of preadipocyte determination. ${ }^{3}$ In response to PPAR activation the ECs lost progressively their structural and molecular characteristics, and formed structurally and biochemically defined adipocytes.

Conclusion: We report morphological and genetic evidence that adipocytes in white and brown fat depots originate from cells that display endothelial characteristics and this is in accordance with the results published by other researchers ${ }^{4}$ and also with previous works performed in our lab. ${ }^{5}$

1. Rodeheffer et al., Cell 2008; 135: 240-249.

2. Tang et al., Science 2008; 322: 583-586.

3. Gupta et al., Nature 2010; 464: 619-623. 
4. Gupta et al., Cell Metab. 2012; 15: 230-9.

5. Cinti et al., J Submicrosc Cytol. 1984;16:243-51.

\section{ELECTRON MICROSCOPY IN PCD}

A. Cangiotti, ${ }^{1}$ M. Pifferi, ${ }^{2}$ S. Cinti ${ }^{1}$

${ }^{1}$ Electron Microscopy Unit, University Hospital "Ospedali Riuniti", Ancona, Italy; 'Department of Paediatrics, University Hospital of Pisa, Italy

E-mail: a.m.cangiotti@univpm.it

Primary Ciliary Dyskinesia (PCD) is a highly heterogeneous genetic disease, associated with defective ciliary structure and function that may result in ineffective mucociliary transport in the airways and consequent chronic oto-sino-pulmonary disease. ${ }^{1}$ Electron microscopy (EM) can distinguish between primary, genetically determined abnormalities, that are specific, universal and permanent and secondary non-specific, acquired lesions, typically transient and focal. ${ }^{2,3}$ However it is technically demanding and sometimes difficult to interpret. To collect a good sample and to obtain an adequate visualization of axonemal structures, the utilization of proper tools is extremely important. An overlapping of lesions between PCD and SCD is frequent because absence of central pair, partial dynein deficiency, shortened dynein arms etc can be primary as well as secondary. ${ }^{4}$ In light of this possible misinterpretation, qualitative and quantitative ultrastructural data for each case must be collected in a specific "table summarizing the ciliary lesions." Authors show their experience in a selected group of 609 case series with a final diagnosis of PCD in 100 cases $(80 \%$ with dynein arm defects, $20 \%$ with central complex/radial spoke defects with or without inner dynein arm defect); Secondary Ciliary Dyskinesia (SCD) in 430 cases, normal ultrastructure in 16 cases, borderline/partial dynein defects in 63 cases. To conclude: 1) EM play an essential role in evaluating suspected cases of PCD although ultrastructural findings sometimes are difficult to interpret and although recently new diagnostic methods became available. ${ }^{4,5} 2$ ) The diagnosis of PCD is especially useful in case of mild or atypical presentation. ${ }^{3}$ For this purpose the group of borderline/partial dynein deficiency is the most intriguing and difficult to interpret. 3) A definitive diagnosis of PCD needs an integrated approach using careful clinical, genetic, functional, as well as ultrastructural studies.

1. Afzelius BA. Int. Rev Exp Path 1979, 19:1-43.

2. Mierau GW et al. Ultrastruct Pathol 1992, 16:245-54.

3. Bush A et al. Am J Respir Crit Care Me 2006, 174:109-11.

4. Jorissen M et al. Acta Otorhinolaryngol Belg 2000, 54:343-56.

\section{ELEMENTAL COMPOSITION OF BREAST MICROCALCIFICATION: COMPARATIVE STUDY IN BENIGN AND MALIGNANT LESIONS}

M. Scimeca, ${ }^{1}$ E. Bonanno, ${ }^{1}$ C.A. Pistolese, ${ }^{2}$ F. Della Gatta, ${ }^{2}$ L.G. Spagnoli ${ }^{1}$

${ }^{1}$ Department of Biopathology, Anatomic Pathology, University of Rome Tor Vergata, Rome, Italy; ${ }^{2}$ Department of Imaging Diagnostic, Molecular Imaging, Interventional Radiology and Radiation Therapy University Hospital "Tor Vergata Rome, Italy

In the UK incidence rates of breast cancer have increased by $50 \%$ over the last 25 years to around 44000 women and 300 men per annum.

Pattern and density properties of mammary calcifications are used to screen by imaging breast cancer without reference to their elemental composition. ${ }^{2}$
In order to characterize microcalcification composition related to pathology and mammography we utilized ultrastructural microanalysis, to analyze the elemental composition of microcalcifications in 30 mammary biopsies. Microcalcifications were taken from tissue sections and processed for the electron microscopy and microanalysis.

The elemental composition of the microcalcifications of the analyzed tissues demonstrated calcium oxalate in $16 \%$, hydroxyapatite in $38 \%$ and Mg-substituted hydroxyapatite (Mg-HA) in $46 \%$ of cases. Noteworthy, hydroxyapatite resulted to be present in the $50 \%$ of hyperplasia, in the $33 \%$ of fibrosis and in the $17 \%$ of carcinomas whereas Mg-HA mainly correlated with the ductal in situ carcinoma, $86 \%$. The density of mammographic $\mathrm{Mg}-\mathrm{HA}$ is greater than hydroxyapatite and calcium oxalate one.

Our data suggest a strong correlation between $\mathrm{Mg}-\mathrm{HA}$ and the ductal in situ carcinoma.

The ability of these calcifications to sequester interstitial magnesium determines a local magnesium deficiency which could favor the carcinogenesis and/or tumor progression mechanisms.

Further studies to correlate mammographic density to the Mg$\mathrm{HA}$, could improve the discrimination of calcification associated to malignant mammary lesions.

1. Botha JL et al. Europ J Cancer 2003;39:1718-29.

2. Hofvind et al. Acta Radiol 2011 52: 481-487.

\section{ULTRASTRUCTURAL AND MICROANALYTICAL STUDY OF A SUBCUTANEOUS GRANULOMA HPV TETRAVALENT VACCINE INDUCED: A CASE REPORT}

M. Scimeca, E. Bonanno, A. Colantoni, A. Volpe, L.G. Spagnoli Dipartimento di Biopatologia, Università di Roma Tor Vergata, Roma, Italy

We report the case of a 18 year old woman who developed a subcutaneous nodular lesion localized on her right upper arm. ${ }^{1,2}$

The lesion was excised by surgical resection and submitted to histological analysis in the surgical pathology laboratory of the University of Tor Vergata.

Part of the sample underwent to electron microscope analysis and ultrastructural investigations by microanalysis technique. Conventional histological examination revealed a lesion consisted of a necrotic/necrobiotic center surrounded by palisading epithelioid histiocytes into the fibroadipous and skeletal muscle tissue. This granulomatous lesion closely resemble deep granuloma annulare or rheumatoid nodule. The histiocytes contained abundant intracytoplasmic violaceous/gray granular material. Pas and Ziehl-Nielsen histochemical stainings resulted negative. The ultrastructural analysis shed light to the elemental composition of the examined granulomatous formation identifying metallic deposits with an emission pick at EDXA for aluminum.

Anamnesti data revealed that the patient was recently submitted to HPV-vaccine inoculums at the site of the granulomatous lesion. It is interesting to note that the adjuvant system of the quadrivalent human papillomavirus vaccine is made of aluminum hydroxide. Therefore the histological and ultrastructural data reported were consistent with the diagnosis of subcutaneous aluminium related granuloma subsequent to the vaccine inoculum.

In conclusion, electron microscopy analysis associated to elemental composition analysis unable us to demonstrate aluminium hydroxide inside the cells of the granulomatous reaction. To the best of our knowledge it is the first ultrastructural 
and microanalytical study of GA post-HPV vaccine injection, no data were found published before. Due to the high frequency of vaccination aluminum granuloma should be included in the differential diagnosis of deep granulomatous reaction in young women.

1. Barron, D.F. et al. (1997) Lippincotts Prim. Care Pract. 1(1), 33 39.

2. Setterfield, J. et al. (1999) Clin. Exp. Dermatol. 24(6), 458-460.

\section{ULTRASTRUCTURAL FEATURES OF A MIXED PITUITARY ADENOMA/CRANIOPHARYNGIOMA}

G. Finzi, ${ }^{1}$ M. Cerati, ${ }^{1}$ S. La Rosa, ${ }^{1}$ A. Marando, ${ }^{2}$ C. Zoia, ${ }^{3}$ E. Piantanida ${ }^{4}$ F. Ferreli, ${ }^{5}$ C. Capella ${ }^{2}$

${ }^{1}$ Department of Pathology, Ospedale di Circolo, Varese, Italy; ${ }^{2}$ Department of Surgical and Morphologic Sciences, University of Insubria, Varese, Italy; ${ }^{3}$ Neurosurgical Clinic of University of Insubria, Varese, Italy: ${ }^{4}$ Departments of Clinical Medicine and Surgical Sciences, Division of Endocrinology, University of Insubria, Varese, Italy; ${ }^{5}$ Department of Otorhinolaryngology, Ospedale di Circolo, Varese, Italy

E-mail: giovanna.finzi@ospedale.varese.it

Mixed pituitary adenoma/craniopharyngiomas are rare tumors, accounting for 15 reported cases. They may represent collision tumors, derived from independent stem cells, or they may derive from a single stem cell undergoing divergent differentiation. This latter hypothesis is supported by the findings of a close commixture between the two tumors showing areas which suggest a transition between the two components, ${ }_{1}^{1}$ and by the immunohistochemical expression of the pituitary transcriptor factor 'steroidogenic factor $l^{\prime}$ ' in the craniopharyngioma component. ${ }^{2}$ Ultrastructural studies of pituitary adenomas associated with Rathke's cleft cysts demonstrated a close proximity between the cells of the two components ${ }^{3}$ and hybrid cells. ${ }^{4}$ In mixed pituitary adenoma/craniopharyngiomas, however, the ultrastructural demonstration of hybrid cells between the two components, suggesting a common histogenesis of the two components of the neoplasm, has not been previously reported.

A 75-year-old woman presenting with diplopia and slight increase of serum prolactin underwent head CT scan and MR which demonstrated a sellar mass. She was operated with an endoscopic endonasal transphenoidal approach with resection of multiple fragments. The tumor was composed by a pituitary ACTH cell adenoma admixed with islands of adamantinomatous craniopharyngioma representing $40 \%$ of the lesion. Electron microscopy showed cells of a sparsely granulated ACTH cell adenoma admixed with a craniopharyngioma component. Some hybrid cells were also identified. The patient completely recovered and 5 months post-operative head MR confirmed the complete resection of the lesion.

1. Gokden M et al. Human Pathol 2009, 40:1189-1193.

2. Yoshida A et al. Am J Surg Pathol 2008, 32:1736-1741.

3. Nishio $S$ et al. Neurosurgery 1987, 21:371-377.

4. Kepes Cancer 1978, 41:337-343.

\section{ULTRASTRUCTURAL EVIDENCE OF ALLERGIC-LIKE HOST REACTION IN HUMAN GASTRIC CARCINOMAS \\ R. Caruso, F. Fedele}

Department of Human Pathology, University of Messina "G. Martino", Messina; Italy

Inflammatory cells and mediators are a key component of the tumour microenvironment ${ }^{1}$ and cancer-related inflamma- tion has been proposed to represent the seventh hallmark of cancer. Electron microscopic studies of 7 surgically excised human gastric carcinomas with tumor-associated tissue eosinophilia (TATE) were done with special emphasis on the host inflammatory responses to tumour. Host cells participating in the inflammatory response included numerous eosinophils, activated macrophages, and mast cells. There was also extracellular deposition of free eosinophil granules and Charcot-Leyden crystals. Most of the tumour-infiltrating mast cells exhibited anaphylactic or piecemeal degranulation, indicating that the mast cells had been activated in situ. These ultrastructural findings are discussed in relationship to a number of recent studies of allergic inflammation in both human and experimental animals. ${ }^{2-5}$

1. Mantovani A. Cancer Cell. 2009;16:173-4.

2. Elishmereni M et al. Allergy. 2011;66:376-85.

3. Minai-Fleminger $Y$ et al. Cell Tissue Res. 2010;341:405-15.

4. Neves JS et al. Curr Opin Immunol. 2009; 21:694-9.

5. Caruso RA et al. Ultrastruct Pathol. 2012;36:139-44

\section{MORPHODYNAMIC EVENTS ON CELL PLASMA MEMBRANE RELATED TO TUMOR PROGRESSION}

I. Giusti, S. D'Ascenzo, G. Di Stefano, V. Dolo

Department of Health Science, University of L'Aquila, Italy

For many years it was believed that communications between cells depend mainly on soluble mediators and their corresponding receptors or on cell to cell contact; it is increasingly clear, instead, that cells are able to release and receive multi-molecular signals contained in small fragments of cell membrane called microvesicles (MVs); the latter can provide information to other cells and deeply modify the surrounding microenvironment.

MVs are shed from the regulated outward blebbing of plasma membrane, they range in size between 100-1000 nm and are characterized by a loss of plasma membrane symmetry, resulting in phosphatidylserine exposure on outer surface. MVs are shed for many type of normal ant cancer cells; in normal cell shedding is an highly regulated phenomenon and in cancer cells, instead, is spontaneous and constitutive.

MVs cargo includes a variety of molecules ranging from proteins (i.e. growth factors, transcription factors, proteolytic enzymes), lipids and nucleic acids (i.e. mRNA, miRNA and DNA) all of which may be transferred horizontally between cells; it's important to note that all these molecules are not a random sample of originating cell molecules but a specific combination of them.

MVs are involved in several physiological processes ranging from pro-coagulant activity, feto-maternal communication, cellular differentiation and immune response. Their role, however, is more recognized in pathological processes, especially in cancer; MVs secreted in tumoral microenvironment contribute to the pro-invasive character of cancer cells (trough enzyme release, drug resistance, establishment of the tumor stem cell niche and modulation of the host immune response), induce oncogenic cellular transformation and stimulate invasion and angiogenesis: they are rich, indeed, in proteolityc enzymes such as gelatinases and cathepsin B able to degrade extracellular matrix allowing invasion trough it; contain, moreover, VEGF, the most important growth factor in inducing angiogenesis. 


\section{ULTRASTRUCTURAL MICROANALYSIS FOR METAL CONTAMINANTS ASSESSMENT IN PLEURO-PULMONARY CANCER}

M. Scimeca, E. Bonanno, A. Volpe, A. Colantoni, L.G. Spagnoli ${ }^{1}$ Dipartimento di Biopatologia, Università di Roma Tor Vergata, Roma, Italy

In the large urban centers of many industrialized countries has been identified a strong correlation between mortality caused by cardio-respiratory diseases and air pollution. ${ }^{1}$ Among the elements which take part of PM 10 and PM 2.5 classification, heavy metals are considered very interesting particles due to their possible toxic effects induced by bioaccumulation. ${ }^{2}$ Toxicity of these elements is well supported by in vitro experimental data. ${ }^{3}$

Anyway, the long term effects induced by bioaccumulation of these elements is still controversial.

In this work lung and pleural tissue samples have been studied through ultrastructural (electron microscopy) and atomicmolecular investigations (microanalysis) in order to identify potential locations for elements by bioaccumulation.

In this study were included 16 cases of mesothelioma, 10 cases of pleural fibrosis, 10 lung cancers and 10 control tissues.

The contaminants that we observed were: chrome, manganese, alluminum, and cobalt in mesothelioma; vanadium, cadmium and zinc in lung cancer; alluminum, silver, cadmium in pleural fibrosis.

Mesothelioma, pleural fibrosis and lung cancer samples explored by microanalysis showed a so surprising variability of elemental composition that let us to suppose that these tissues could be have an anatomo-functional predisposition for the elements bioaccumulation.

The presence of metallic elements in the examinated tissues rises two fundamental questions:

Is bioaccumulation of pollutants to be considered as a primary insult for the tumorigenesis or rather is it to be related to intrinsic characteristics of tumor tissue that, for unknown reasons, tend to behave as a storage tissue of the elements?

Could bioaccumulation of these elements represent the "missing link" for the understanding of the relationship inflammation / tumor, or vice versa?

The data presented in this work, if they were supported by other experimental evidence, could shed new light on the relationship between environment, genetics and human health.

1. Gill EA et al. (2011) Prog Cardiovasc Dis. 2011 MarApr;53(5):353-60.

2. Stanek LW et al. (2011)Toxicol Sci. 2011 Mar;120 Suppl 1:S8-27. Epub 2010 Dec 8.

3. Donaldson K et al. (1997) Environ Health Perspect. 1997 Sep;105 Suppl 5:1285-9.

\section{PATTERNS OF VACUOLIZATION IN HUMAN METAPHASE II OOCYTES AFTER CRYOPRESERVATION: ULTRASTRUCTURAL ASPECTS}

S.A. Nottola, ${ }^{1}$ M.G. Palmerini, ${ }^{2}$ C. Lorenzo, ${ }^{2}$ E. Albani, ${ }^{3}$ M. Maione, ${ }^{1}$ E. Di Marco, ${ }^{2}$ G. Macchiarelli, ${ }^{2}$ G. Coticchio, A. Borini, ${ }^{4}$ P.E. Levi Setti ${ }^{3}$

${ }^{2}$ Dept. of Anatomy, Histology, Forensic Medicine and Orthopaedics, La Sapienza University, Rome; ${ }^{2}$ Dept. of Health Sciences, University of L'Aquila; ${ }^{3}$ IRCCS Istituto Clinico Humanitas, Dept. of Gynecology and Reproductive Medicine,

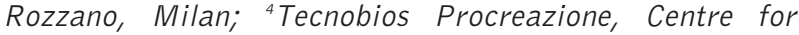
Reproductive Health, Bologna, Italy

E-mail: stefania.nottola@uniromal.it
Vacuolization is a structural dysmorphism of the ooplasm of human mature (MII) oocytes subjected to cryopreservation, likely related to the type and/or concentration of the cryoprotectants. In the present study human MII oocytes cryopreserved by slow freezing were fixed at different time intervals during thawing and observed by light and transmission electron microscopy ( LM and TEM), with the aim to determine at what stage of the freeze-thawing procedure the vacuoles may form and develop. Oocytes, obtained from consenting IVF patients, were subjected to freezing through two-step propanediol $(\mathrm{PrOH})$ dehydration with $0.75-1.5 \mathrm{~mol} / \mathrm{l}$ and $0.2 \mathrm{~mol} / \mathrm{l}$ sucrose (S). The oocytes were fixed in glutaraldehyde at sampling (controls) and during thawing, after being transferred in $1.0 \mathrm{~mol} / / \mathrm{PrOH}$ and $0.3 \mathrm{~mol} / \mathrm{l} \mathrm{S}$ for $5 \mathrm{~min}$ (group A: to study freezing effect), then in $0.5 \mathrm{~mol} / \mathrm{l} \mathrm{PrOH}$ and $0.3 \mathrm{~mol} / / \mathrm{S}$ for additional 5 min (group B: to study early thawing effect) and finally placed in $0.3 \mathrm{~mol} / \mathrm{l} \mathrm{S}$ for $10 \mathrm{~min}$ (group C: to study late thawing effect). The oocytes were then processed for LM and TEM. Vacuoles, were only occasionally detected in the ooplasm of controls. Vacuoles of different sizes and shapes were numerous in all cryopreserved oocytes. By TEM vacuoles appeared as empty spaces lined by a membrane often interrupted. Differences in number of vacuoles between fresh control and cryopreserved samples were statistically significant $(P<0.05)$. Vacuoles, present in group $A$, increased during thawing: reached the maximum amount in group $B$ and then decreased at the end of thawing. These data not only evidenced that vacuolization is a recurrent form of cell damage during slow freezing, but also demonstrated that vacuoles primarily form during freezing and may further increase in number at thawing, particularly during the $\mathrm{PrOH}$ step-wise dilution.

\section{MORPHOLOGICAL ASPECTS OF HUMAN AGED OOCYTES: AN IN VIVO AND IN VITRO ULTRASTRUCTURAL STUDY}

S. Bianchi, ${ }^{1}$ M. Maione, ${ }^{2}$ S. Cecconi, ${ }^{1}$ G. Micara, ${ }^{3}$ A. Linari, ${ }^{3}$ D. Tranquilli, ${ }^{3}$ C. Aragona, ${ }^{3}$ G. Macchiarelli, ${ }^{1}$ S.A. Nottola ${ }^{2}$ ${ }^{2}$ Dept. of Health Sciences, University of L'Aquila, L'Aquila; ${ }^{2}$ Dept of Anatomy, Histology, Forensic Medicine and Orthopaedics, and ${ }^{3}$ Dept. of Obstetrics, Gynaecology and Urology, La Sapienza University of Rome, Rome, Italy E-mail: stefania.nottola@uniromal.it

Maternal age affects the outcome of Assited Reproductive Tecnologies by worsening oocyte quality and competence. The ultrastructure characteristics of aged human oocytes have not been not fully studied. Therefore, we analyzed oocytes donated by women $<35$ and $\geq 35$ years old, after informed consent. MII oocytes, fixed at time of pick up (in vivo) or after 24 hours culture (in vitro aging) were evaluated by light and transmission electron microscopy. All IN VIVO samples showed a normally shaped oocyte surrounded by a regular ZP and expanded cumulus. Their ooplasms were rich in organelles and provided with a homogenous matrix. Ooplasmic mitochondria-SER aggregates (M-SER) were significantly reduced in number/size and partially replaced by mitochondria-vesicle complexes $(M V C)$ in $\geq 35$ years old patients. In the same patients, cortical granule and microvilli patterns were significantly altered. All IN VITRO aged samples showed a compact cumulus with rare cumulus cell-oocyte contacts. The inner ZP showed an increased density in $\geq 35$ years old patients. M-SER were rare or totally absent in all samples. MVC were present in all samples, increased up in number and often showed abnormal vesicles in $\geq 35$ years old patients. All samples showed numerous lysosomal structures and reduction of cortical granules. Microvilli significantly decreased in density and shortened in 
$\geq 35$ years old patients. In conclusion, several significant ultrastructural changes occurred in fresh oocytes (in vivo) from older patients and in all 24 hours in vitro culture aged oocytes. The ultrastructure changes observed in in vitro culture aged oocytes resembles in vivo aging-related damages and are significantly more evident in oocytes from older patients. The alterations here reported may be considered as ultrastructural markers of oocyte aging.

\section{IS ELECTRON MICROSCOPY STILL USEFUL IN THE DIAGNOSIS OF KUFS DISEASE?}

S. Valente, ${ }^{1}$ U. Aguglia, ${ }^{2}$ M. Bisceglia, ${ }^{3}$ G. Pasquinelli ${ }^{1}$

${ }^{1}$ Surgical Pathology Unit, University Hospital St. OrsolaMalpighi, Polyclinic of Bologna, Bologna, Italy; ${ }^{2}$ Regional Epilepsy Centre, "Bianchi-Melacrino-Morelli" Hospital, Reggio Calabria, Italy; 'Department of Pathology, IRCCS "Casa Sollievo della Sofferenza" Hospital, San Giovanni Rotondo (FG), Italy

Kufs disease (KD) or adult neuronal ceroid-lipofuscinoses (NCL) is an adult onset neurodegenerative disease belonging to the group of inherited lysosomal storage disorders characterized by accumulation of auto-fluorescent storage material in many cell types, including neurons. ${ }^{1}$ Clinical, neuroimaging and neurophysiological findings are not specific. Consequently, the ultrastructural detection of intracellular lipofuscin deposits containing organized fingerprint (FP) lamellae is necessary for in vivo diagnosis of $\mathrm{KD} .{ }^{1}$ Lysosomal storage material may be detectable both in neuronal and in non-neuronal cells. Biopsies on rectal mucosa are considered as essential in the diagnosis of KD. ${ }^{2}$ Rectal biopsy is easy to perform, scarcely traumatic and cost-effective. ${ }^{2,3}$ Moreover, FP inclusions have not been reported in aging and are regarded as highly specific for NCL. Recently, mutations in the CLN6 gene in 6/6 families with suspicion of KD were described. ${ }^{4}$ The negativity of this mutation in a patient previously reported by our group, who presented atypical clinical features of KD diagnosed by rectal biopsy, ${ }^{5}$ prompted us to retrospectively examine our data on rectal biopsy in patients with suspicion of KD. By reviewing the ultrastructure of rectal mucosa samples from 13 patients with suspicion of KD and 52 patients with Irritable Bowel Syndrome (controls) we found FP inclusions in patients from both groups. FP inclusions were mostly located in VSMC; ganglion cells were never seen. ${ }^{6}$ By reviewing 440 renal biopsies we found identical FP inclusions in VSMC of renal arterioles of human kidneys. ${ }^{7}$ We conclude that the value of superficial rectal biopsy as a diagnostic tool in KD is limited. Future studies should evaluate if their presence in submucosal or whole thickness biopsies including ganglion cells may improve their presumptive diagnostic value.

1. Goebel HH, Wisniewski KE. Current state of clinical and morphological features in human NCL. Brain Pathol 2004; 14: 61-69.

2. Ceuterick-de Groote C, Martin JJ. Extracerebral biopsy in lysosomal and peroxisomal disorders. Ultrastructural findings. Brain Pathol 1998; 8: 121-132.

3. Pasquinelli G, Cenacchi G, Le Piane $E$, et al. The problematic issue of Kufs disease diagnosis as performed on rectal biopsy: a case report. Ultrastruct Pathol 2004; 28: 43-48.

4. Arsov $T$, Smith $K$, Damiano J, et al. Kufs disease, the adult form of neuronal ceroid lipofuscinosis, caused by mutations in CLN6. Am J Hum Genet 2011; 88: 566-573.

5. Gambardella A, Pasquinelli G, Cittadella R, et al. Kufs' disease presenting as late onset epilepsia partialis continua. Neurology 1998; 51: 1180-1182.

6. Ferlazzo E, Gasparini S, Pasquinelli G, et al. Usefulness of rectal biopsy for the diagnosis of Kufs disease: a controlled study and review of the literature. Eur J Neurol. 2012 May 8.

7. Bisceglia M, Carosi I, D' Errico M, et al. Lipofuscinlike granules of the juxtaglomerular apparatus of the kidney. The diagnostic significance of a quasi-normal subcellular structure incidentally encountered in the course of routine ultrastructural evaluation of renal biopsies. Pathol Res Pract 2011; 207: 79-85. 



\section{Index of authors}

A

Aguglia U. 9

Albani E. 8

Angelini C. 3

Aragona C. 8

B

Badiali De Giorgi L. 3,4

Baldassarri V. 3,4

Battistelli M. 3

Bianchi S. 8

Bisceglia M. 9

Boldrini R. 2

Bonanno E. 6,8

Borini A. 8

Burattini S. 3,4

C

Cangiotti A. 6

Canonico B. 3,4

Capella C. 7

Capello G. 5

Cartechini E. 1

Caruso R. 7

Cecconi S. 8

Cenacchi G. 2,3,4

Cerati M. 7

Cinti S. 5,6

Citti A. 2

Colantoni A. 6,8

Corvera S. 5

Coticchio G. 8

Curzi D. 4

D

D'Ascenzo S. 7

Danhaive 0.2

Della Gatta F. 6

Di Bella P. 1

Di Marco E. 8

Di Stefano G. 7

Dolo V. 7

F

Falcieri E. 3,4

Fanin M. 3

Fedele F. 7

Ferreli F. 7

Finzi G. 7
Foli A. 5

Frontini A. 5

Fusconi M. 4

G

Gealekman 0. 5

Giusti I. 7

Graziano C. 4

L

La Rosa S. 7

Levi Setti P.E. 8

Linari A. 8

Lodi R. 4

Lorenzi T. 1

Lorenzo C. 8

M

Macchiarelli G. 2,8

Maione M. 8

Marando A. 7

Marzioni D. 1

Merlini L. 1

Merlini G. 5

Micara G. 8

Morbin M. 1

Morbini P. 5

Morroni M. 1

N

Nottola S.A. 2,8

P

Palladini G. 5

Palmerini M.G. 8

Papa V. 3,4

Papa S. 3,4

Pasquinelli G. 9

Paulli M. 5

Peca D. 2

Pegoraro E. 3

Pellegrini C. 1

Petrini S. 2

Pianese L. 1

Piantanida E. 7

Pifferi M. 6

Pistolese C.A. 6
R

Ragno M. 1

Rinaldi R. 4

S

Sabatelli P. 1

Salaroli R. 3,4

Salucci S. 3,4

Sardone F. 1

Scarpelli M. 1

Scimeca M. 6,8

Spagnoli L.G. 6,8

T

Tagliavini F. 1

Tarantino L. 3,4

Tidball J.G. 4

Tranquilli D. 8

V

Valente S. 9

van Tran K. 5

Verga L. 5

Volpe A. 6,8

Z

Zingaretti M.C. 5

Zoia C. 7 
